\title{
SISTEM INFORMASI PENGELOLAAN ASET KENDARAAN BERMOTOR PADA STMIK RAHARJA TANGERANG
}

\author{
Diah Aryani ${ }^{1}$ \\ Muhamad Arif Nurdin ${ }^{2}$ \\ Pandi Baskara ${ }^{3}$
}

\begin{abstract}
Dosen STMIK Raharja Tangerang ${ }^{1}$, Mahasiswa STMIK Raharja Tangerang ${ }^{2,3}$
Jl Jenderal Sudirman no.40, Modern, Cikokol Tangerang ${ }^{1,2,3}$

Email : diah.aryani@ raharja.info' ${ }^{1}$,arif@ raharja.info ${ }^{2}$, pandi.baskara@ raharja.info ${ }^{3}$
\end{abstract}

\begin{abstract}
ABSTRAK
Perkembangan teknologi saat ini semakin pesat dan sudah berpengaruh pada kegiatan organisasi untuk mendapatkan data dan informasi secara cepat. Sehingga penggunaan komputer sangat penting dalam memperlancar dan mempermudah dalam proses pengelolaan data untuk mencapai tujuan. Pada Perguruan Tinggi Raharja proses laporan pengelolaan aset kendaraan bermotor yang di lakukan secara manual yang mengakibatkan proses pencarian data dan pelaporan data aset memerlukan waktu dan juga sering kali data tersebut ada yang hilang yang berpengaruh pada proses pemeliharan aset kendaraan. Oleh karena itu diusulkan untuk merancang sistem informasi manajemen aset kendaraan menggunakan php dan mysql. Yang bertujuan untuk mampu mengatasi kesulitan dalam mencari data yang diinginkan dan keterlambatan pemeliharaan aset kendaraan dan dalam pembuatan laporan.
\end{abstract}

Kata kunci: sistem, aset, informasi.

ABSTRACT

The development of technology is currently growing rapidly and has been influential in the organization's activities to obtain data and information quickly. So the use of computers is essential in expediting and simplifying the process of data management to achieve the goal. In Higher Education Prog asset management reporting processes in motor vehicles is done manually resulting data search process and reporting of data assets requires significant time and too often there is missing data that affect the process of asset maintenance vehicles. It is therefore proposed to design a vehicle asset management information system using php and mysql. Which aims to be able to overcome the difficulty in finding the desired data and vehicle and asset maintenance delay in making the report.

Keywords: systems, assets, information,

\section{Pendahuluan}

\section{Latar Belakang}

Perkembangan ilmu pengetahuan di segala bidang dalam era globalisasi saat ini begitu pesat, seiring dengan kebutuhan pemakai (user). Untuk memperoleh suatu karya atau inovasi yang maksimal serta memperoleh kemudahan dalam membantu melakukan aktivitas pekerjaan sehingga dapat mencapai suatu tujuan. Komputer merupakan salah satu perangkat teknologi yang dapat digunakan sebagai sarana media informasi , Kebutuhan akan suatu sistem informasi ini mencakup hampir di segala ruang lingkup kehidupan. Setiap organisasi sangat membutuhkan informasi yang akurat, cepat, dan relevan. Termasuk untuk melakukan 
pengawasan dan pemeliharaan terhadap aset-aset penting yang di miliki oleh STMIK Raharja agar lebih terstruktur dan memudahkan untuk melakukan controling terhadap aset-aset tersebut.

Perguruan Tinggi Raharja bermula dari sebuah lembaga kursus komputer yang bernama LPPK (Lembaga Pendidikan dan Penelitian Komputer) Raharja yang terletak di Jl. Gatot Subroto km.2 Harmoni Mas Cimone Tangerang. LPPK Raharja diresmikan pada tanggal 3 Januari 1994 oleh bapak walikota Tangerang Drs. H. Zakaria Mahmud, seiring berjakan nya waktu maka LPPK Raharja telah resmi menjadi Sekolah Tinggi Manajemen Informatika dan Komputer (STMIK) RAHARJA. Dengan surat keputusan Nomor 42/01/YNN/PR/II/2000. Lembaga pendidikan tersebut masih menggunakan metode manual dalam melakukan pengelolaan terhadap aset kendaraan, yang dilakukan dengan mengunakan form kertas untuk melakukan pencatatan terhadap aset tersebut, proses tersebut dirasa kurang efektif karna file kertas tersebut mudah rusak atau pun hilang dalam pengarsipan.

\section{Tujuan}

Dapat dijadikan fasilitas dalam mengelola aset-aset yang di miliki STMIK Raharja agar pengelolaan nya menjadi lebih efektif dan modern serta memberikan pengaruh yang baik pada STMIK Raharja, Meminimalkan penggunaan kertas yang selama ini di jadikan sebagai pencatatan dan monitoring aset kendaraan, serta memudahkan dalam melakukan kegiatan pencatatan dan montring aset tersebut.

\section{Metodologi}

Peneliti menggunakan beberapa metode, pertama dengan menggunakan metode pengamatan atau observasi dengan cara peneliti mendatangi STMIK Raharja Tangerang yang berlokasi di J1. Jend. Sudirman, Babakan, Kec. Tangerang, Kota Tangerang untuk mendokumentasikan serta mengumpulkan data-data yang diperlukan dalam membuat laporan hasil penelitian antara lain data pemeliharan aset kendaraan mulai dari penggantian oli mesin, penggantian filter oli, penggantian filter udara dan tune up kendaraan. Kedua dengan metode wawancara atau interview yaitu peneliti melakukan wawancara kepada pihak-pihak yang terkait dalam hal ini adalah divisi operasi STMIK Raharja untuk memenuhi data yang diperlukan dalam pembuatan laporan hasil penelitian. Selain dari metode pertama dan kedua pada metode ke tiga ini peneliti juga menggunakan metode studi pustaka dengan mengumpulkan data dari berbagai referensi seperti internet, buku, dan perpustakaan untuk melengkapi data yang diperlukan.

\section{Rumusan Masalah}

Berdasarkan hasil riset dan diskusi dengan bagian operasi di perguruan tinggi raharja, tentang pengelolaan manajemen aset kendaraan bermotor di Perguruan Tinggi Raharja, pelaksanaan nya masih dilakukan dengan cara pencataatan pembukuan manual, sehingga pengelolaan nya dirasa belum optimal, sistem manual seperti ini membuat petugas kewalahan dalam mengelola dan membuat laporan manajemen aset kendaraan, kesulitan dalam mencari data yang diinginkan dan keterlambatan dalam pembuatan laporan karena dalam pengecekan data, pencarian data, dan pembuatan laporan petugas pun harus mencari kembali berkas berkas yang telah di simpan sebelumnya.

Dari permasalahan tersebut maka untuk mempermudah dalam melakukan pengelolaan aset tersebut di butuhkan sebuah sistem infromasi sehingga proses tersbut dapat berjalan dengan efektif dan efisien. 


\section{Tinjauan Pustaka}

Pengertian sitem informasi didefinisikan sebagai berikut: Sistem informasi adalah suatu sistem di dalam suatu organisasi yang mempertemukan kebutuhan pengolahan transaksi harian, mendukung operasi, bersifat manajerial dan kegiatan strategi dari suatu organisasi dan menyediakan pihak luar tertentu dengan laporan-laporan yang diperlukan [2].

Manajemen Aset adalah ilmu dan seni untuk memandu pengelolaan kekayaan yang mencakup proses merenca- nakan kebutuhan aset, mendapatkan, menginvestasi, melakukan legal audit, menilai, mengoprasikan, meme- lihara, membaharukan atau menghapuskan hingga mengalihkan aset secara efektif dan efisien[1].

Tujuan utama dari manajemen aset adalah membantu suatu organisasi dalam memenuhi tujuan penyediaan pelayanan secara efektif dan efisien[4]. Sedangkan sasaran dari manajemen aset adalah untuk mencapai kecocokan atau kesesuaian sebaik mungkin antara aset dengan strategi penyediaan pelayanan[4].

Pengertian Unified Modelling Languange (UML): UML adalah sebuah bahasa pemodelan yang menjadi standart dalam industri software untuk visualisasi, merancang, dan mendokumentasikan sistem perangkat lunak yang akan di buat.[3].

Terdapat penelitian yang sebelumnya dilakukan mengenai sistem informasi aset diantaranya adalah

Penelitian yang dilakukan oleh Endriawan pada tahun 2013 dengan judul "Pengembangan Sistem Pemantauan Aset Teknologi Informasi Pada PT. Pertamina" Menjelaskan bahwa penelitian tesebut adalah melakukan penelitian untuk merancang sebuah sistem informasi yang dapat mengelola aset, meliputi, mencatat aset perusahaan pada unit operasi, mencatat aset perusahaan pada cost center mencatat aset perusahaan yang dibawa oleh pekerja, memungkinkan sentralisasi pencatatan aset perusahaan sehingga dapat mengawasai aset perusahaan, membantu pelaporan aset teknologi informasi dan membantu proses perpanjangan kontrak aset teknologi informasi pada vendor.

Dan juga Penelitian yang dilakukan oleh dewi puspitasari dengan judul "Analisa Sistem Penunjang Keputusan Dalam Pengelolaan Aset Perusahaan Oleh Divisi Fixed Aset dan IT Financial Control Pada PT. Nestle Indonesia Cikupa Factory" . yang menjelasakan tentang pengelolaan aset yang di lakukan oleh PT. Nestle Indonesia Cikupa Factory tidak spesifik dan bersifat konvensional oleh sebab itu penulis tersebut menggunakan metode SAP untuk mempermudah pengelolaan aset tersebut.

\section{Pembahasan}

\section{Sistem yang berjalan saat ini}

Dalam menggambarkan sistem yang berjalan saat menggunakan UML singkatan dari Unified Modelling Language.Selama melakukan penelitian di Perguruan Tinggi Raharja, sistem yang berjalan saat ini pada proses pengelolaan aset kendaraan masih bersifat manual diantaranya laporan perawatan kendaraan kampus yang masih menggunakan excel lalu di print seperti Tabel 1. berkut.

\begin{tabular}{|c|c|l|}
\hline $\begin{array}{c}\text { Nama } \\
\text { Kendaraan }\end{array}$ & $\begin{array}{c}\text { nomer } \\
\text { plat }\end{array}$ & $\begin{array}{l}\text { Rangka } \\
\text { Mesin }\end{array}$ \\
\hline
\end{tabular}


AVANZA

B1430CFX

JP 58696

\begin{tabular}{|c|c|c|c|c|c|c|c|}
\hline \multirow{2}{*}{$\mathrm{NO}$} & \multirow[t]{2}{*}{ Uraian } & \multicolumn{2}{|c|}{ Realisasi } & \multicolumn{2}{|c|}{ Realisasi } & \multicolumn{2}{|c|}{ Realisasi } \\
\hline & & $\mathrm{KM}$ & $\mathrm{Tgl}$ & $\mathrm{KM}$ & $\mathrm{Tgl}$ & $\mathrm{KM}$ & $\operatorname{Tgl}$ \\
\hline 1 & Oli mesin & & & 1300 & $\begin{array}{c}30- \\
\text { Nov- } \\
12\end{array}$ & 12500 & $\begin{array}{r}15- \\
\text { Jan- } \\
14\end{array}$ \\
\hline 2 & Filter oli & & & & & 12500 & $\begin{array}{r}15- \\
\text { Jan- } \\
14\end{array}$ \\
\hline 3 & Ganti Busi & & & 1300 & $\begin{array}{c}30- \\
\text { Nov- } \\
12\end{array}$ & & \\
\hline 4 & Filter udara & & & & & & \\
\hline 5 & Minyak rem & & & & & & \\
\hline 6 & Roda & & & & & & \\
\hline 7 & $\begin{array}{l}\text { Oli } \\
\text { transmisi }\end{array}$ & & & 1300 & $\begin{array}{c}30- \\
\text { Nov- } \\
12 \\
\end{array}$ & & \\
\hline 8 & Ganti Ban & & & & & & \\
\hline 9 & $\begin{array}{l}\text { Filter } \\
\text { Bensin } \\
\end{array}$ & & & & & & \\
\hline 10 & Tune up & 508 & $\begin{array}{c}05- \\
\text { Sep- } \\
12 \\
\end{array}$ & & & 12500 & $\begin{array}{r}15- \\
\text { Jan- } \\
14 \\
\end{array}$ \\
\hline 11 & & & & & & & \\
\hline 12 & & & & & & & \\
\hline
\end{tabular}

Tabel 1. Laporan Perawatan Aset Kendaraan secara manual

\section{Analisa sistem yang berjalan pada use case Dagram}

Use Case prosedur sistem yang berjalan dijelaskan pada Gambar 1. berikut dengan penjelasan antara lain :

- 1 sistem yang berjalan dalam melakukan perawatan rutin (Service) kendaraan di Perguruan Tinggi Raharja

- 4 actor yang melakukan kegiatan yaitu, Supir, Kabag, Asdir Operasi, Direktur

- 9 use case yang biasa dilakukan oleh aktor actor. 


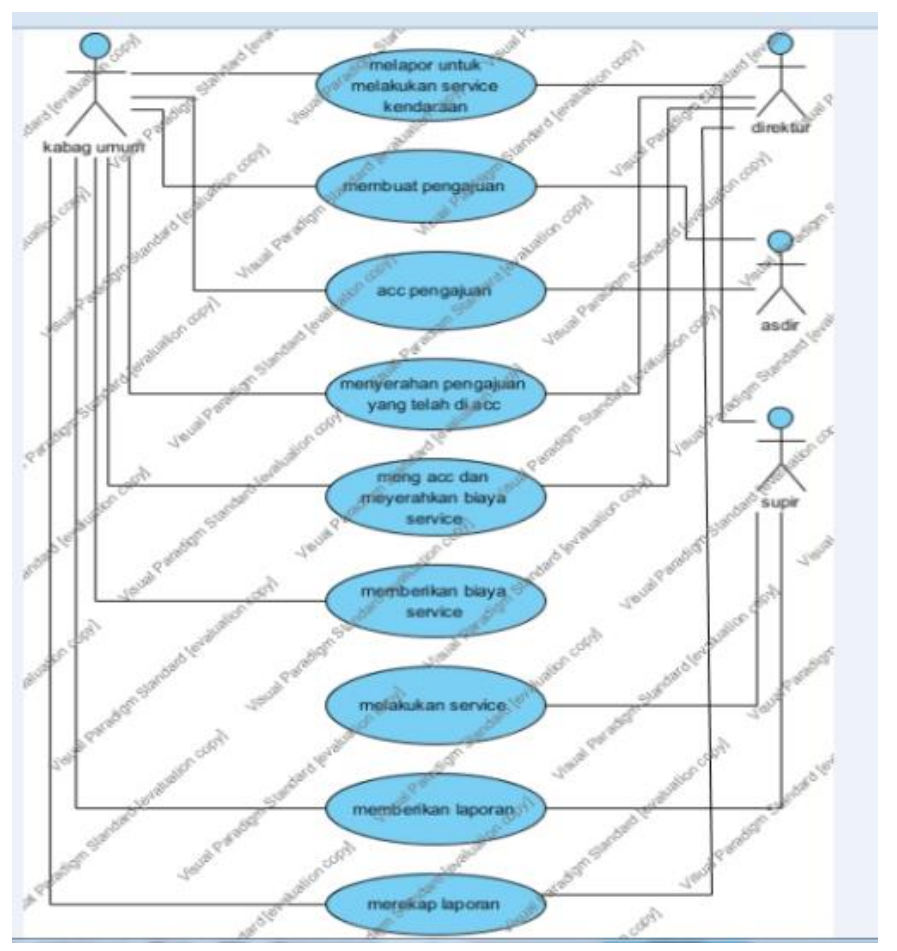

Gambar 1. Use case prosedur yang berjalan

\section{Analisa Sistem yang Berjalan Menggunakan Activity Diagram}

Analisis Sistem yang berjalan menggunakan activity diagram dijelaskan pada Gambar 2. dibawah ini.

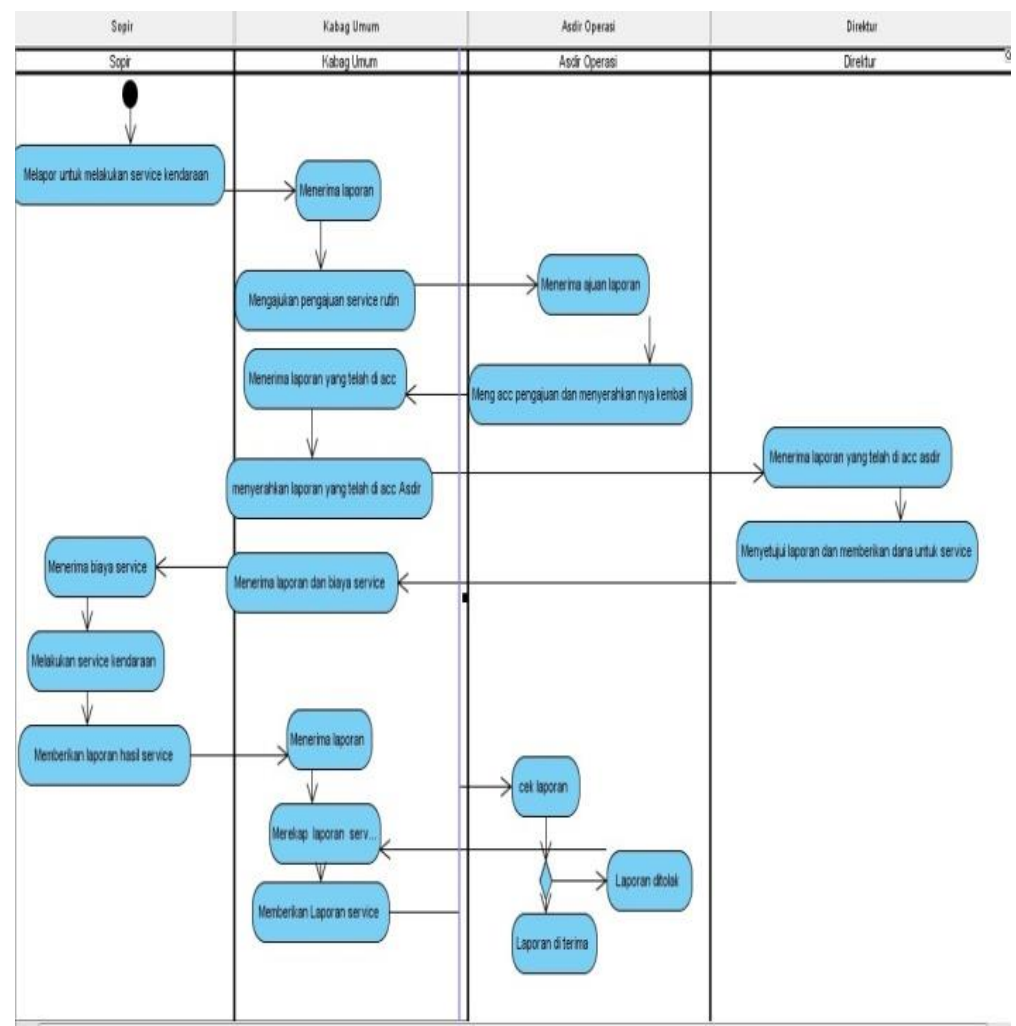

Gambar 2. Activity Diagram prosedur yang berjalan 


\section{Tujuan Perancangan}

Penelitian ini akan dilakukan pada lembaga pendidikan STMIK Raharja Tangerang, dimana lembaga pendidikan tersebut memiliki pengelolaan aset kendaraan bermotor yang masih di lakukan dengan cara konvensional menggunakan kertas.

\section{Konsep Perancangan Dan Pembahasan}

Pada perancangan saat ini yang dimaksudkan meliputi perancangan perangkat lunak(software) dalam hal Pengelolaan aset kendaraan

Alat dan software yang digunakan meliputi :

1. Laptop Acer Aspire E14

2. Software sublime text.

3. Software Xampp

4. Software MySql

\section{Perancangan Perangkat Lunak (Software)}

Perancagan perangkat lunak adalah melakukan penulisan listing program ke dalam software sublime text dengan menggunakan bahasa pemrograman php dan freamwork yii2, dimana perintah-perintah program tersebut akan di eksekusi oleh sistem yang dibuat.

\section{a. Penulisan Listen Program Pada Software sublime text}

Pada perancangan perangkat lunak menggunakan software Sublime text untuk menuliskan listing program dan menyimpannya. Software Sublime text di gunakan sebagai media untuk mengetikkan code program yang di butuhkan dalam website pengelolaan aset Adapun code program yang di buat untuk menjalankan website pengelolaan aset dapat dilihat seperti pada Gambar 3. sebagai berikut :

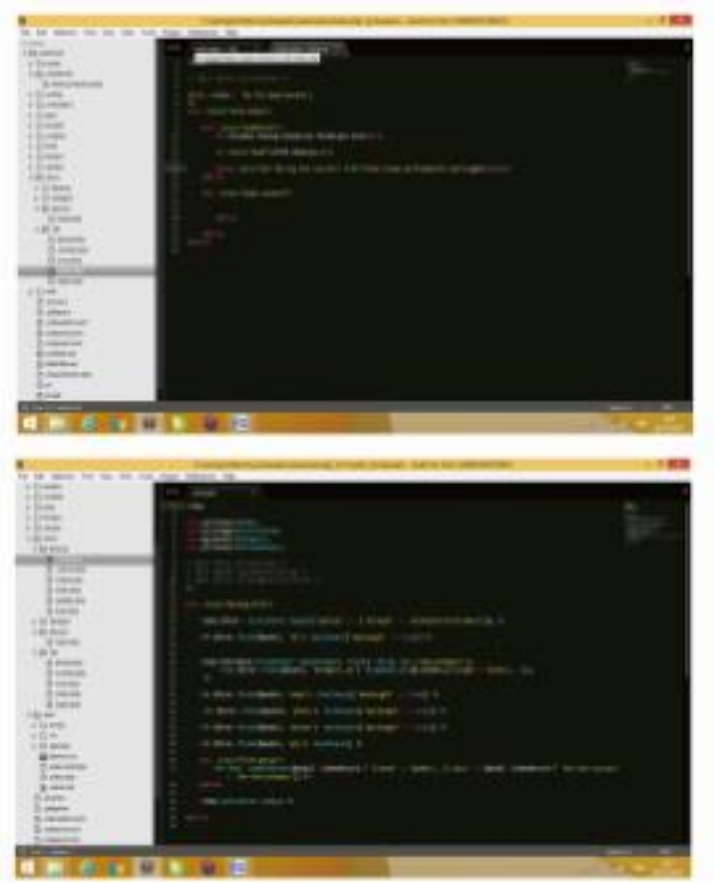

Gambar 3.Code Program Pada Software Sublime Text

Setelah code program ditulis semua, langkah selanjutnya adalah proses kompilasi dengan menghubungkan seperti yang dijelaskan pada Gambar 4. Kemudian dengan database data 
data aset tersebut di input dan tersimpan pada website aset tersebut.

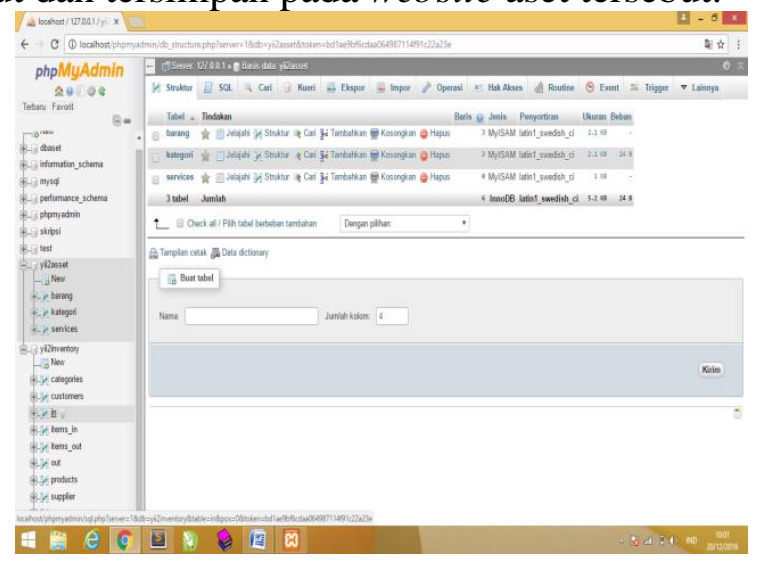

Gambar 4. Data base

Proses pemanggilan databese dengan menggunakan sublime text dijelaskan pada Gambar 5. Dibawah ini :

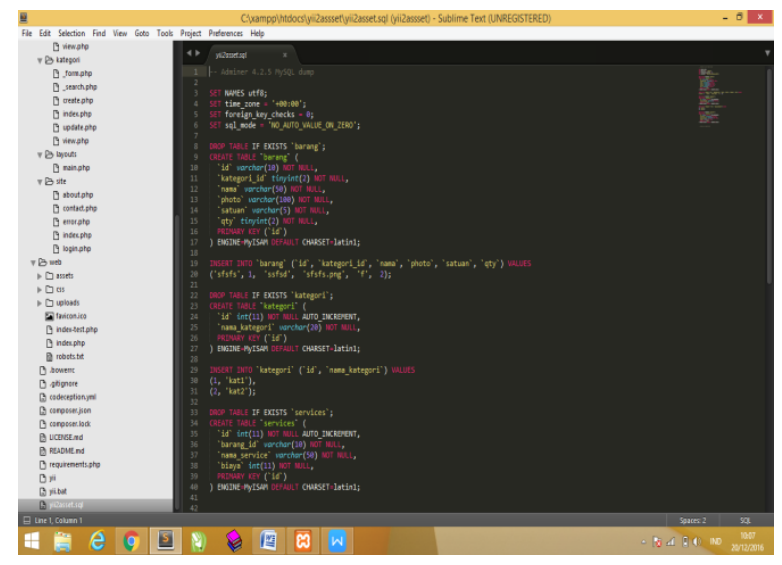

Gambar 5. Proses Pemanggilan data base

\section{Implementasi dan Pengujian}

\section{Implementasi}

Setelah sistem dianalisis dan didesain, maka akan menuju tahap implementasi. Implementasi sistem merupakan tahap meletakkan sistem sehingga siap untuk dioperasikan. Implementasi bertujuan untuk mengkonfirmasi modul-modul perancangan, sehingga pengguna dapat memberi masukan kepada pengembang sistem.

Implementasi antarmuka dilakukan dengan setiap halaman web yang dibuat dan pengkodeannya dalam bentuk file program. Berikut ini adalah implementasi antarmuka yang dibuat dan dibedakan antara antarmuka untuk Divisi operasi bagian administrator dan Kepala Divisi beberapa contoh tampilan antar muka sistem yang sudah diimplementasikan beerupa tampilan kategori asset seperti Gambar 6. Berikut. 


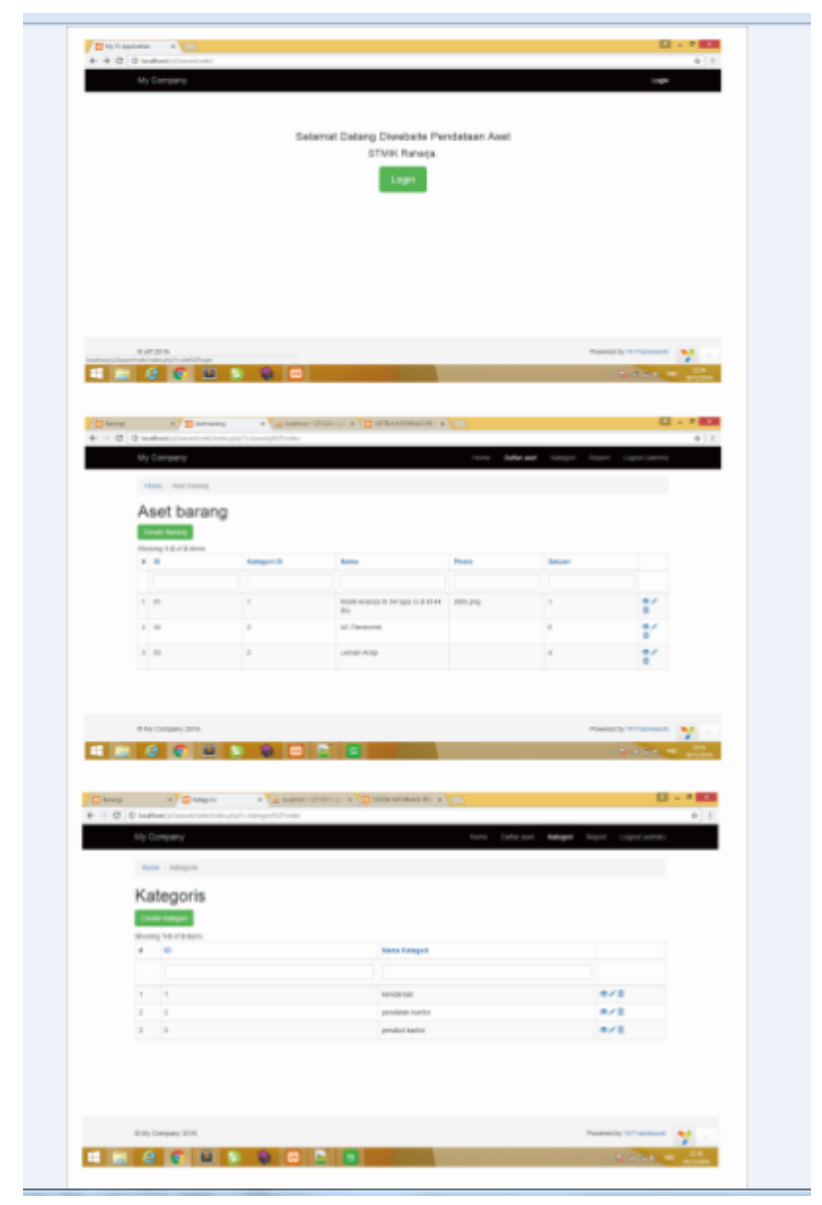

Gambar 6. Tampilan katagori aset

\section{Data Pencatatan Laporan Aset Kendaran Secara Manual}

Berikut Gambar 7. merupakan data pencatatan laporan ketepatan waktu dalam melakukan pencatatan yang berkaitan langsung dengan pemeliharaan aset kendaraan pada Perguruan Tinggi Raharja secara manual.

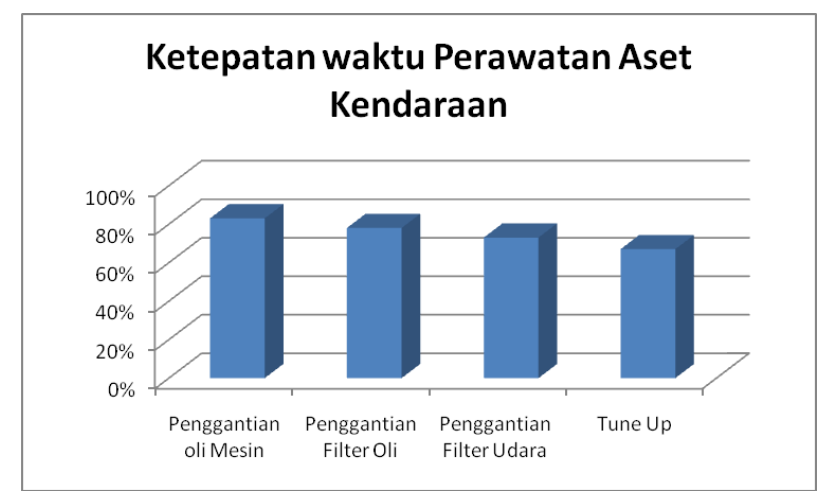

Gambar 7. Laporan Aset Kendaraan Secara Manual

Data Pencatatan Laporan Aset Kendaran Menggunakan Web Sistem Informasi Managemen Aset

Pada Gambar 8. merupakan data pencatatan laporan ketepatan waktu dalam melakukan 
pencatatan yang berkaitan langsung dengan pemeliharaan aset kendaraan pada Perguruan Tinggi Raharja menggunakan Web Sistem Informasi Managemen Aset.

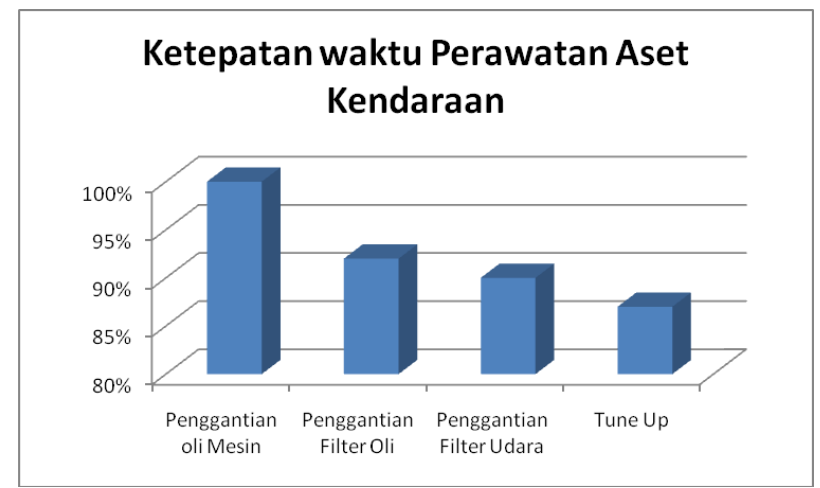

Gambar 8. Laporan Aset Kendaraan dengan Web Sistem Informasi Managemen Aset

Dari data tersebut dapat dilihat bahwa pencatatan laporan asset kendaraan secara manual ratarata ketepatan waktu dalam pemeliharaan asset kendaraan adalah 68,75\% sedangkan pencatatan laporan asset kendaraan menggunakan Web Sistem Informasi Managemen Aset memiliki ketepatan waktu dalam pemeliharaan asset kendaraan sebesar 92,25\%. Hal ini dapat menunjukan bahwa dengan menggunakan Web Sistem Informasi Managemen Aset menjadi lebih terkomputersasi dan angka keterlambatan dalam pemeliharaan asset kendaraan menurun sebesar $23,5 \%$.

\section{Pengujian}

Pengujian Pengujian yang digunakan untuk menguji sistem yang baru adalah metode pengujian black box. Pengujian black box berfokus pada persyaratan fungsional perangkat lunak. Rencana pengujian yang akan dilakukan dengan menguji sistem secara alpha dan beta. Pengujian Sistem Informasi Aset Perusahaan berikut menggunakan data uji berdasarkan data aset yang ada pada STMIK. Raharja Tangerang.

\section{Kesimpulan}

Berdasarkan hasil analisa yang telah diuraikan sebelumnya, maka dapat diambil kesimpulan yaitu:

"Penggunaan sistem informasi manajemen aset dapat melakukan pemrosesan data yang diinput dari perangkat-perangkat yang diprogram sebagai media inputan memberikan kemudahan petugas dalam mengelola dan membuat laporan manajemen aset kendaraan sehingga mampu mengatasi kesulitan dalam mencari data yang diinginkan dan keterlambatan dalam pembuatan laporan karena dalam pengecekan data, pencarian data dan pembuatan laporan juga menjadi lebih mudah tanpa harus mencari kembali berkas berkas yang telah di simpan sebelumnya."

\section{Daftar Pustaka}

1. Elmi Fuziati“PERANCANGAN SISTEM INFORMASI MANA

JEMEN ASET DI KECAMATAN PASAR KEMIS”.STMIK Raharja Tangerang 2015

2. Utami Dewi Widianti. "PEMBANGUNAN SISTEM INFORMASI ASET DI PT.INDUSTRI TELEKOMUNIKASI INDONESIA (PERSERO) BERBASIS WEB, Jurnal Ilmiah Komputer dan Informatika (KOMPUTA)57 Volume. I Nomor. 2, Bulan Oktober 2012 
3. dewi puspitasari dengan judul "Analisa Sistem Penunjang Keputusan Dalam Pengelolaan Aset Perusahaan Oleh Divisi Fixed Aset dan IT Financial Control Pada PT.Nestle Indonesia Cikupa Factory".STMIK Raharja Tangerang, 2014.

4. Indah Safarina dkk. "Perencanaan Arsitektur Perusahaan untuk Pengelolaan Aset di PT. Musdalifah Group menggunakan Kerangka Kerja Zachman”, Journal of Information Systems Engineering and Business Intelligence Vol. 1, No. 2, October 2015 